\title{
Systemic change: Rational and emotional elements
}

\author{
MIKE HANNIBAL' and NADARAJAH SRISKANDARAJAH ${ }^{2}$ \\ ${ }^{1}$ Mentor Consulting Pty Ltd, PO Box 500, Windsor, NSW 2756, Australia \\ ${ }^{2}$ School of Agriculture \& Rural Development, University of Western Sydney, Hawkesbury, Bourke Street,
}

Richmond, NSW 2753, Australia

\begin{abstract}
A series of composite case studies is used to explore some effects of agricultural change on farmers. The "grower", the "opportunist", the "tuner" and the "passenger" are presented as representing a range of true life scenarios, to illustrate how many of the assumptions about the relationship between the farmer and extension worker hinder the fostering of change processes.
\end{abstract}

Keywords: change, emotions, extension workers, farmers, human relationships, rationality, systemic change

\section{Introduction}

Discussion of change, in agricultural terms, is most often set within the context of that most discussed of relationships-the extension worker and the farmer. We will argue that many of the assumptions that have driven this relationship are nbt useful for the fostering of rich and useful change processes.

Change is something that human beings undertake. This must be axiomatic to any discussion of the subject. Though a simple axiom, it is the one that is most often forgotten. Its implications are that any process of change and the attendant relationships are mediated by our behaviour as human beings. Many authors have discussed the role of emotion in the process of change We shall explore that role in this paper.

We have chosen to use a series of composite case studies as our vehicle for the exploration of agricultural change. These case studies have arisen from our work with farmers over the last decade or more. We should be very clear that none of these case studies is representative of any one farmer with whom we have had contact. Rather they represent a useful typology of farmers with whom we have worked.

\section{Change}

Maturana \& Varela (1987) discussed the biology of cognition and its impact on "... social communication and knowledge transfer". What was interesting about their work was both the circumstance -it was prepared for the Organisation of American States to aid them in understanding the process of the community change and development-and the content. They argued that all processes of human communication are mediated by the ever-changing biological structure of the humans involved. Much of this structural change is in turn mediated by our emotions.

The next important feature of change is the way in which we perceive it. Almost certainly change is a continuing process, is ever present, and has a continual impact on our daily lives. What is equally certain is that many of us choose to see change as a series of intermittent perturbations interspersed with long periods of stability. Often this choice of view is determined by individuals' needs to preserve the stability of their daily life.

Finally in this very brief scene setting we wish to explore two other assumptions which underlie firstly our views of change and secondly our views of the change relationship discussed above. Most extension workers arc trained in a scientific positivist tradition. In such a tradition black and white is prized above all shades of grey. Situations can only be described as either/or. They are either good or bad; right or wrong; effective or ineffective. Such a positivist view has a number of effects, perhaps most important is the impact which is has on the extension relationship.

Secondly, all change mediated in such relationships tends to be seen, a priori, as "good". Such positivism leaves no room for more relativistic approaches where a particular change might be seen as "alright for some".

\section{The cases}

\section{The grower}

The grower has plans, he' can tell you about them; where he's headed to; why he's headed there; how he's going to get there and how long it's going to take. He is extremely proactive in his approach to his work. He sees himself as a business entrepreneur who is using

I. Overwhelmingly the people in these stories are male. This has several reasons, the most important of which is the almost total predominance of males in the farmers we have worked with as farmers This is not to belittle the role of women in farming families but to suggest that their role is often in the broader enterprise rather than at the level of the farming activity within that enterprise. 
information from management, business, finance and other sectors, just as much as he's using information on animal health, pastures or farm planning.

What makes the grower special is that his use of information is self-driven and he is able to seek resources for himself. If extension officers are part of the information resources used, then they are used proactively with the farmer asking for the information he requires. He already knows what he wants to know and where he can get it.

Change for the grower is well controlled, desired and highly managed. $\mathrm{He}$ is keen to grow the enterprise, often to increase income, to place himself at a greater distance from the physical running of the farm and to employ his developing skills in the management of the inevitable labour. In the view of the grower the only path to a better lifestyle is through the growth of the enterprise. He seeks out opportunities to purchase more land to enable him to actualise the plan which he has developed.

The grower is likely to be in the 30-50 age group. $\mathrm{He}$ can see a life after farming. Farming is the business in which he is utilising his talents as a manager, planner and entrepreneur. It is not the only business in which he could be happy, but it's almost certainly the preferred business.

\section{The opportunist}

The opportunist is different. He is almost certainly driven by goals, it's just that he couldn't tell you about them and they are certainly ill-defined and global. The most common goal for the opportunist is security. He might not be able to tell you about it, but if you watch him you'll see it. The farm next door comes on the market, and apparently with hardly a moment's thought, he's bought it. The farm on the other side comes on the market, snap and he's bought it too.

There is no grand plan, he can't tell you why he's doing it or where he's heading. What he can tell you is that opportunity never knocks twice. If you fail to take the chance when it arises, then you'll wait a long time for your next chance. Once you have the new farm it's time to think about just how you'll use it and what you'll need to do to make it fit into the enterprise. It's amazing, though, once you've bought the new farms then one of the kids will say "Dad, I'd like to come home and try my hand at farming". One opportunity just breeds another. You've got to take them when they come.

The opportunist will be older, 40-55, and much less open than the grower. People will mistake both of them as greedy acquisitors. Their neighbours often think that it's just money and land for the sake of greed. Nothing could be farther from the truth. By the way, the last person the opportunist wants to see is an extension person. What can they possibly offer to him?

\section{The tuner}

Now here's the group we've all been waiting for. This is the group that extension strategies are designed for. The tuner is there to make the enterprise run better, to make the sheep clip an extra half a kilo, to get another 100 kilograms of milkfat per hectare, to make life easier for themselves. The tuner is the new age of agriculture. He's not about production per se, he's more interested in efficiency.

Over at least 20 years the extension messages, the technology on sale, has been predominantly aimed at the tuner. It's a case of "we can help you do what you do do well boy". The thoughtful tuner looks at technology and works out how it can work for him. His relationship with extension workers is close but not wholly uncritical. He knows that what he's doing is not so easy but he's determined to keep twitching and tuning until he gets a benefit and then to work just as hard for the next benefit.

Its just a pity that he only comes along about 2 times in every 100 farmers in many places. Indeed sometimes the tuners are all but hidden by the growers and the opportunists.

\section{The passenger}

He's a passenger on the good ship Agricultural Enterprise, cruising the gentle seas, without an apparent care in the world. He's got enough money to see him through and he's happy just the way he is. The thing about the passenger is that he's the one who sometimes doesn't realise that the light at the end of the tunnel is an express train roaring down on top of him.

The passenger often has odd goals. He might only be 40 but his planning may well be about the day he can get out of farming. It's not that he doesn't like it, it's just that it doesn't mean much to him. He probably fell into it, it's not a bad way to make a living but it'll be nice to get out. Then again the passenger almost certainly knows little beyond farming so he's not entirely sure that he does want to get out.

The strange thing about the passenger is that suddenly, and apparently completely out of character, he'll buy 200 hectares next door. "Why did he do that?" the neighbourhood asks. The answer is often simple. The passenger has his eye on his exit from farming. If that 200 hectares makes it easier for him to sell to some young fellow then it's a good thing to do.

The passenger is a nice fellow. He often likes to do a good job, he might come to a field day sometimes. But he's not going to be a world-beater, he's got a vision of the house in town. 


\section{Interpretation}

The cases offered above, although perhaps not precisely true for all geographical locations, offer a range of true to life scenarios which we can work with effectively. They raise a number of issues which we would like to explore further.

Let's for a moment come back to the suggestion that the extension relationship is the one that we are currently interested in. Traditionally it has been the most important relationship with regard to agricultural change. Although that is increasingly not so, it is nevertheless a significant part of the change process.

\section{Homogeneity versus plurality}

Within such a relationship extension organisations have traditionally focused on the development and delivery of extension programmes. These programmes are built around good technologies which are thought to offer benefits to farmers. They ride, however, on a number of assumptions. Firstly they assume homogeneity of population. They assume that all farmers are the same and that their needs are similar. Many extension personnel argue that this is not their view. The extension programmes show their reliance upon this assumption however. Our cases have shown that farmers are not an homogeneous group. Indeed when said baldly like that it seems painfully obvious. Yet extension workers continue to behave as if the reverse were true.

We claim that'any extension programme, to work effectively, must be designed at the farm level. We do not suggest that the wheel should be continually reinvented, rather that each farmer must be provided the opportunity to mix and match those elements and technologies which suit them. This is the only effective approach to the extension relationship.

\section{Service provision versus service access}

Agricultural extension has been a little like the social security system; Once you're signed on they'll just keep coming back. It is assumed that everyone needs extension services. It is clear to us from our work that this is not the case. Let us be clear, we do not mean "need" in terms of some absolute judgement of need, rather we mean in terms of individuals' assessment of their own needs. This is the only assessment that has any relevance.

If we look at the grower, we see that they are in general aggressive seekers of information. Their way of operating generates for them a need for information. They are aggressive in setting both the information agenda and in seeking out those who can provide for that agenda. Contrast this approach with the opportunist who is very little interested in external information. On the face of it, both farmers may appear to be doing the same thing. In real terms, however, they are subject to quite different drivers and assess their own needs quite differently.

The culture of "universal extension", although it has undergone some modification, is still dominant, It has, however, no basis in reality. Thus the constant cry of extension officers "we can only ever access $30 \%$ of farmers; why can't we get more of them involved?", is indicative of the needs of the extension worker. It has nothing to do with the farmer. We have never met a farmer who is unable to get the advice of a lawyer when he feels he needs it. Why should access to extension services be any different?

\section{Culturally desirable and systemically feasible}

This leads us to another part of the explanation for the ways in which people approach change. We argue that all change must be both culturally desirable and systemically feasible. In the context of farmers this means that whatever change is undertaken must be desirable within the culture of the individual human activity system, the farm and its environment, and it must also be feasible within that human activity system. We often pay heed to the second of these conditions. "Can he afford it?", "Is his country suitable?" are oft asked questions. Our experience is that most potential change does not get to the feasibility test. It is rejected as culturally undesirable.

Our passengers are a vivid example of this. All too often in traditional extension contexts they have been typified as laggards. They do not in general access extension services or many other services. They do, however, engage in what appear to be uncharacteristic activities, buying the block next door for instance. It is only when you ask them about what drives them that you understand that the apparently uncharacteristic action is to them extremely desirable. Thus it can move to the feasibility test and on to action.

\section{One step back represents two steps forward}

The agricultural sectors of most countries have a long history of attempting to implement change for improvement in production and later efficiency. In this framework, the change desired by extension institutions and government is seen as inherently good. And if a little change is good then more must be better.

Increasingly it has become apparent that sustainability, from an economic and ecological perspective, may best be served by a reduction in the intensity of our enterprises or indeed in the "undoing" of some of the change of the past. Several examples come to mind. Perhaps the most simple is in government developed farming settlements such as those developed by the 
Lands and Survey Department in New Zealand. Many of these settlements were completely cleared of existing vegetation. More recent development has seen the reintroduction of trees. Perhaps more telling was the development of continuous cropping systems in the Victorian Mallee. These systems had been developed at research stations with the Mallee, they promised greater yields and productivity from land with $250-375 \mathrm{~mm}$ annual rainfall. Such land had traditionally been conservatively farmed with extensive use of moisture conserving fallows. Initially the newer, more intensive farming systems appeared to offer significant benefits. Later many farmers using these systems suffered severe losses. The systems required high inputs and made high demands on environmentally sensitive country. They proved to be unsustainable even with very small adverse changes to weather patterns.

\section{Conclusion}

Change in agriculture, whether we are aware of it or not, is a continuing process. It is not a discontinuous series of incremental, linear events. In the context of the extension relationship fundamental reappraisal of our construction of change is necessary before we can move forward.

Farming is a human activity system. Such a notion is built upon an understanding of the attitudes, feelings, values and emotions of those involved. As professionals in agriculture we cannot be effective until we understand and acknowledge the role of each of these elements for the farmers we work with.

Once we have begun this process of understanding we also become part of the human activity system where we are not selling change but joining with farmers to learn our way through complex and changing situations.

Such relationships are characterised by their diversity and indeed their uniqueness. It becomes inevitable that any acceptance of this view of change means that wC need to listen to farmers rather than telling them about their needs. Such approaches will lead to highly developed processes of mutual participation for the future.

\section{REFERENCES AND READING}

Bateson, Gregory. 1972. Steps to an ecology of mind. Ballantine Books, New York.

Maturana, Humberto; Varela, Francisco. 1987. The tree of knowledge: the biological roots of human understanding. Shambhala Books, Boston.

Senge, Peter. 1990. The fifth discipline: the art and practise of the learning organisation. Doubleday, New York.

Uphoff, Norman. 1992. Learning from Gal Oya: Possibilities for participatory development and post Newtonian social science. Cornell University Press, Ithaca. 